\title{
Plasma Fueling, Pumping, and Tritium Handling Considerations for FIRE
}

\author{
P. W. Fisher ${ }^{1}$, M. J. Gouge ${ }^{1}$, C. A. Foster ${ }^{1}$, B. E. Nelson ${ }^{1}$, C. A. Gentile ${ }^{2}$ and the FIRE Study Team \\ ${ }^{1}$ Oak Ridge National Laboratory, P.O. Box 2009, Oak Ridge, TN 37831-8071 \\ ${ }^{2}$ Princeton Plasma Physics Laboratory, P.O. Box 451, Princeton, NJ 08543
}

\begin{abstract}
Tritium pellet injection will be utilized on the Fusion Ignition Research Experiment (FIRE) for efficient tritium fueling and to optimize the density profile for high fusion power. Conventional pneumatic pellet injectors, coupled with a guidetube system to launce pellets into the plasma from the high field side, low field side, and vertically, will be provided for fueling along with gas puffing for plasma edge density control. About $0.1 \mathrm{~g}$ of tritium must be injected during each 10 -s pulse. The tritium and deuterium will be exhausted into the divertor. The double null divertor will have 16 cryogenic pumps located near the divertor chamber to provide the required high pumping speed of 200 torr-L/s.
\end{abstract}

\section{INTRODUCTION}

The plasma fueling system design for FIRE is based on previous designs for CIT, BPX and ITER as well as more recent developments and plasma physics results in the area of pellet launch from multiple locations relative to the magnetic axis. The goal is to produce a flexible fueling system that would require minimum change in the progression from FIRE to ITER or a fusion demonstration (DEMO) plant.

The fueling system [1, 2] must maintain the required plasma density (near the empirical Greenwald density limit), establish a density gradient for plasma particle (especially helium ash) flow to the edge, and supply hydrogenic edge fueling for increased scrape-off layer flow for optimum divertor operation. Another function is to inject impurity gases at low flow rates for divertor plasma radiative cooling and wall conditioning. The plasma fueling system may also provide for plasma discharge termination on demand via massive gas puffing or injection of cryogenic mass via pellets or liquid jets. A concept called isotopic fueling [3] can be used to improve the tritium burn fraction by limiting use of tritium fuel to only those functions related to the fusion burn and using deuterium for edge density control. This can reduce in-vessel tritium inventories and the required tritium-breeding ratio for fusion reactors.

There is an incentive to maximize the tritium plasma fueling efficiency due to the cost and safety implications of a large tritium throughput and the complexity of reprocessing large torus exhaust gas loads [3]. Generally, in diverted discharges of the larger tokamaks, gas fueling efficiency is in the range of $1-10 \%$, and pellet fueling efficiency is an order of magnitude larger $[4,5]$. Fueling efficiency generally improves with pellet penetration and recent results from ASDEXUpgrade [6] show substantial improvements in both penetration and efficiency for high field launch.

Deuterium pellet injection from four different poloidal locations has been used in experiments on the DIII-D tokamak [7-9] to investigate several aspects of plasma confinement and density control (see Fig. 1). Resulting density profiles show that pellet mass deposition from pellets launched from the high field side (HFS) is well inside the expected penetration radius; this suggests that a drift of the pellet ablatant is occurring toward the low field side (LFS) edge of the plasma (Fig. 2). The formation of highly peaked density profiles with pellets injected from the HFS is possible at higher heating power than is possible from pellets injected from the LFS.

\section{FIRE FUELING SYSTEM}

The FIRE fueling system will use a combination of gas puffing and pellet injection to achieve and maintain burning plasmas. This combination will provide a flexible fueling source with D-T pellets penetrating beyond the separatrix to sustain the 


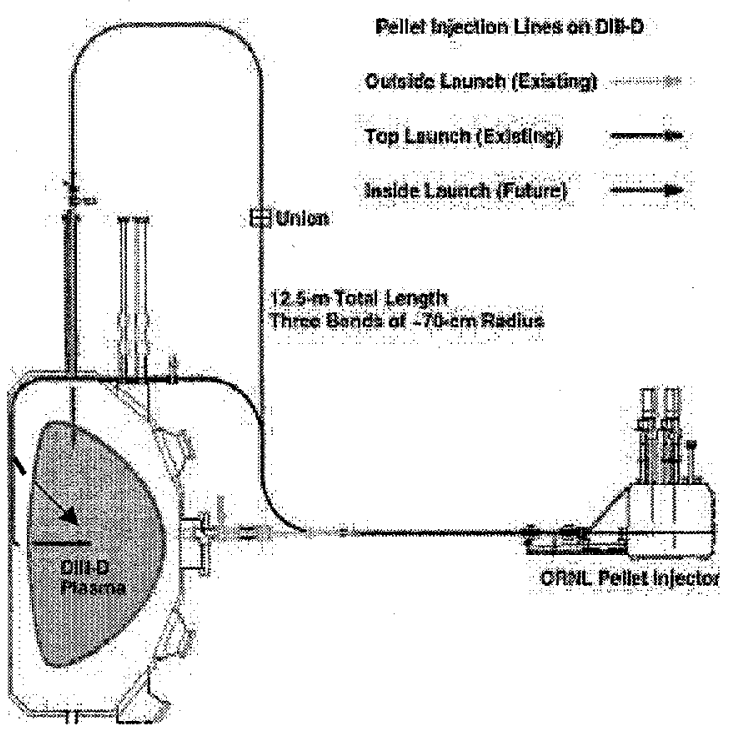

Figure 1. Pellet launch locations on DIII-D.

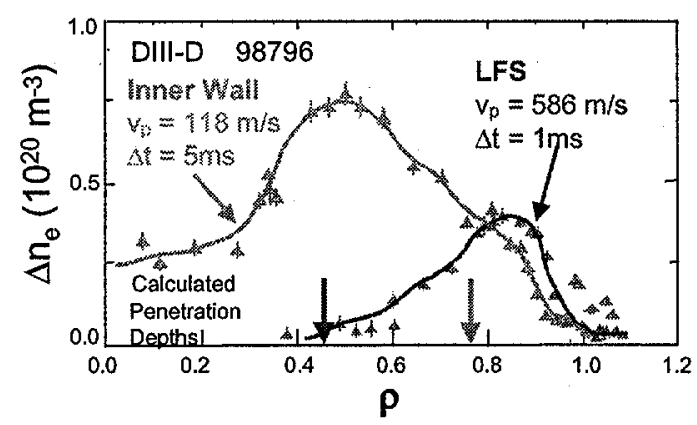

Figure 2. Plasma density increase from a pellet launched from the inner wall (HFS) launch compared with launch from the outer wall (LFS).

burning fusion plasma and deuterium-rich gas fueling the edge region to meet divertor requirements. The fueling system includes a conventional gas puffing system, using all-metal electromagnetic dosing valves (four toroidal stations at two poloidal locations at each divertor level) and a pellet injection system.

The FIRE pellet fueling system (PFS) design includes a long-pulse pneumatic pellet injector system capable of injecting $\mathrm{D}_{2}, \mathrm{D}-\mathrm{T}$, or tritium. It will be comprised of repeating pneumatic injectors using an extruder-based hydrogenic feed system configured to inject pellets using propellant gas for pellet acceleration (up to $1.5 \mathrm{~km} / \mathrm{s}$ ) and/or mechanical punch accelerators (up to $100 \mathrm{~m} / \mathrm{s}$ for pellet injection into curved guidetubes for vertical or HFS launch). The mechanical punch operating alone or with a small amount of propellant gas would reduce considerably the need for differential pumping of the pellet injection line and the reprocessing requirements for propellant gas. The PFS comprises a pneumatic pellet injector with three separate pellet extruders/guns, installed in a containment area. The hydrogenic feed for the injector is provided by a conventional linear piston hydrogen extruder (sized for a 20-s supply of pellets) or by a continuously rotating screw extruder. Deuterium, tritium, and D-T pellets up to $10 \mathrm{~mm}$ in size have been extruded at rates up to $0.26 \mathrm{~g} / \mathrm{s}$ [10]; this pellet size and feed rate are sufficient for fueling fusion reactors at the gigawatt power level. Table 1 shows preliminary parameters for the FIRE hydrogenic fueling system. The technology to deliver intact pellets at the highest possible speeds around curved surfaces (guidetubes) is under development $[8,9]$.

\section{FIRE PUMPING SYSTEM}

The current baseline design is a set of refrigerated duct D-T cryocondensation/diffusion pumps backed by turbo/drag pumps. This system is designed to pump in both the free-molecular and viscous flow regimes. Water is pumped on the inside diameter of the $160-\mathrm{mm}$-diam. by $1 \mathrm{-m}$ long $30 \mathrm{~K}$ entrance duct that connects the divertor to the cryocondensation pump. Other impurity gases and hydrogen are pumped by liquid-helium-cooled cryocondensation pumps. The 2-torr-L/s helium gas produced by the D-T fusion reaction is compressed by viscous drag in the entrance duct by a factor of up to 100 . The compressed helium gas is carried from the cryopump to a turbo/drag pump located outside the biological shield through the divertor duct. The design D-T throughput is 200 torr-L/s for the $20-\mathrm{s}$ pulse length. The partial pressures prior to a 


\begin{tabular}{|c|c|c|c|}
\hline Parameter & Gas Fueling System & $\begin{array}{l}\text { Pellet Fueling } \\
\text { System }\end{array}$ & Remarks \\
\hline Design fueling rate & 200 torr $-\mathrm{L} / \mathrm{s}$ for $20 \mathrm{~s}$ & 200 torr $-\mathrm{L} / \mathrm{s}$ for $20 \mathrm{~s}$ & \begin{tabular}{|c|} 
Torus pumping capacity is \\
200 torr-L/s \\
\end{tabular} \\
\hline $\begin{array}{l}\text { Operational fuel } \\
\text { rate }\end{array}$ & $100-175$ torr $-\mathrm{L} / \mathrm{s}$ & $100-25$ torr $-\mathrm{L} / \mathrm{s}$ & Isotopic fueling \\
\hline $\begin{array}{l}\text { Normal fuel } \\
\text { isotope }\end{array}$ & $\begin{array}{l}\mathrm{D}(95-99 \%) \\
\mathrm{T}, \mathrm{H}(5-1 \%)\end{array}$ & $\begin{array}{c}\mathrm{T}(40-99 \%) \\
\mathrm{D}(60-1 \%)\end{array}$ & D-rich in edge, $T$-rich in core \\
\hline Impurity fuel rate & 25 torr-L/s & $\begin{array}{c}\text { TBD } \\
\text { (prefer gas for } \\
\text { impurity injection) }\end{array}$ & $\begin{array}{c}25 \text { torr-L/s reduces DT fuel } \\
\text { rate due to fixed pumping } \\
\text { capacity }\end{array}$ \\
\hline Impurity species & $\mathrm{Ne}, \mathrm{Ar}, \mathrm{N}_{2}$, other? & TBD & TBD \\
\hline $\begin{array}{c}\text { Rapid shutdown } \\
\text { system }\end{array}$ & Massive gas puff & $\begin{array}{c}\text { "Killer"pellet or } \\
\text { liquid D jet }\end{array}$ & $\begin{array}{c}\text { For disruption/VDE } \\
\text { mitigation }\end{array}$ \\
\hline $\begin{array}{c}\text { Pellet sizes } \\
\text { (cylinder diameter) }\end{array}$ & $\mathrm{N} / \mathrm{A}$ & $3,4,4 \mathrm{~mm}$ & $\begin{array}{c}3 \mathrm{~mm} \text { for density rampup, } \\
4 \mathrm{~mm} \text { for flat-top }\end{array}$ \\
\hline
\end{tabular}

Table 1. Preliminary FIRE fueling system parameters.

discharge are $10^{-7}$ torr for fuel gases $(\mathrm{H}, \mathrm{D}$, and T) and $10^{-9}$ torr for impurities. There will be a total of 16 cryopumps with 8 each top and bottom (at alternate divertor ports) located $1 \mathrm{~m}$ into the pump duct from the double-null divertor. The duct behind the cryopump will be constructed with transverse optically opaque, shielding baffles that will allow $200-\mathrm{L} / \mathrm{s}$ helium gas conductance per port to the turbo/drag pumps located outside the biological shield. There are no moving parts inside the torus.

A layout of the cryopumps is shown in Fig. 3. The cryopumps are designed to have a low mass and active helium gas cooling. Between shots the helium flow will be stopped to allow the pumps to regenerate into the compound turbo/drag pumps. This will limit the tritium contained on the cryopumps to less than $1 \mathrm{~g}$ for a 20 -s. discharge. Gas will be returned to the tritium system where it will be processed through an impurity removal step and a cryogenic distillation system that will separate the hydrogen isotopes and purify the D-T for return to the fueling system.

During the tokamak discharge the effective pumping speed for 200 -torr-L/s flow is $2,000 \mathrm{~L} / \mathrm{s}$ per duct $(32,000 \mathrm{~L} / \mathrm{s}$ total) at the divertor for D-T, $\mathrm{He}$, and impurities. After the shot the pumps will be warmed and regenerated. The 4,000 torr $-\mathrm{L}$ of D-T pumped during the shot will raise the $18-\mathrm{m}^{3}$ torus chamber to 0.2 torr. The pumping time constant for the 16 turbo-drag pumps with $3,200-\mathrm{L} / \mathrm{s}$ combined speed will be $6 \mathrm{~s}$. Between discharges, with the cryopumps warmed to $100 \mathrm{~K}$, the turbo/drag pump set will have a speed of $3,200 \mathrm{~L} / \mathrm{s}$ for all gases. Prior to the discharge, with the pumps cold, in the free molecular flow regime, the pump set will have an effective speed of $16,000 \mathrm{~L} / \mathrm{s}$ for $\mathrm{D}_{2} ; 6,400 \mathrm{~L} / \mathrm{s}$ for air; $46,000 \mathrm{~L} / \mathrm{s}$ for water vapor; and $3,200 \mathrm{~L} / \mathrm{s}$ for helium. The 16 turbo/drag pumps can be backed with a single $3.3-\mathrm{L} / \mathrm{s}$ scroll pump backed with a metal diaphragm pump.

Other tritium systems at FIRE will include tritium gas cleanup systems, tritium monitoring for process control and personnel protection, and negative pressure zones for tritium confinement. The anticipated tritium inventory for FIRE is $<30 \mathrm{~g}$, which would classify FIRE as a Category 3 , low hazard nuclear facility in 
accordance with the criteria detailed in DOE Standard 1027-92.

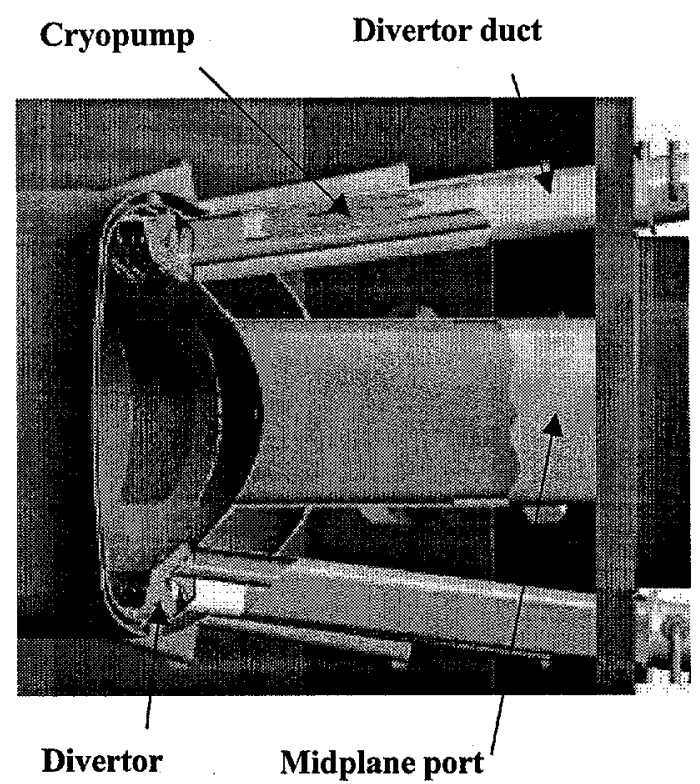

Figure 3. Elevation view of FIRE torus showing divertor duct and cryopump.

\section{ACKNOWLEDGEMENTS}

Work supported by U.S. Department of Energy under contract DE-AC05-96OR22464 with Lockheed Martin Energy Research Corp. and DEAC02-76-CHO03073.

\section{REFERENCES}

1. M. J. Gouge et al., "The CIT Pellet Injection System: Description and Supporting R\&D," Proceedings of the 13th Symposium on Fusion Engineering, Vol. II, p.1240, IEEE 1990.

2. M. J. Gouge, "Fuelling of ITER -Scale Fusion Plasmas," Fusion Technology, 34, 435 (1998).

3. M. J. Gouge et al., "Fuel Source Isotopic Tailoring and Its Impact on ITER Design, Operation and Safety," Fusion Technology, 28, 1644 (1995).

4. L. R. Baylor et al., "Deposition of Pellets into Tokamak Plasmas," Fusion Technology, 34, 425 (1998).

5. L. R. Baylor et al., "Pellet Injection into Hmode Plasmas on DIII-D," to be published in $26^{\text {th }}$ Europ. Conf. on Contr. Fusion and Plasma Physics (1999).

6. P. T. Lang et al., "High-efficiency Plasma Refueling by Pellet Injection from the High-Field Side Asdex Upgrade," Phys. Rev. Lett. 79, 1478 (1997).

7. S. K. Combs et al., "Experimental Study of Curved Guide Tubes for Pellet Injection," Proc. 1997 IEEE/NPSS $17^{\text {th }}$ Symp. Fusion Eng., San Diago, 1102 (1998).

8. S. K. Combs et al., "High-Field-Side Pellet Injection Technology," Fusion Technology, 34, 419 (1998).

9. S. K. Combs et al., "New Pellet Injection Schemes on DIII-D," to be published in the proceedings of this conference.

10. P. W. Fisher and M. J. Gouge, "TPOP -II: Tritium Fueling at a Reactor Scale," Fusion Technology, 34, 515 (1998). 